\title{
Movimento LGBT no Brasil: violências, memórias e lutas
}

\section{LGBT movement in Brazil: violence, memories and struggles \\ Movimiento LGBT en Brasil: violencias, memorias y luchas}

\author{
Vinícius Ferreira ${ }^{1, a}$ \\ Editor convidado \\ viniciusf.c@hotmail.com | https://orcid.org/oooo-0001-7236-4995 \\ Igor Sacramento ${ }^{2, b}$ \\ Editor científico da Reciis \\ igor.sacramento@icict.fiocruz.br | https://orcid.org/0000-0003-1509-4778
}

\footnotetext{
${ }^{1}$ Universidade Federal do Rio de Janeiro, Escola de Comunicação. Rio de Janeiro, RJ, Brasil.

${ }^{2}$ Fundação Oswaldo Cruz, Instituto de Comunicação e Informação Científica e Tecnológica em Saúde. Rio de Janeiro, RJ, Brasil.
}

a Mestrado em Comunicação e Cultura pela Universidade Federal do Rio de Janeiro.

b Doutorado em Comunicação e Cultura pela Universidade Federal do Rio de Janeiro.

Palavras-chave: Movimento LGBT; Comemorações; Memórias; Lutas; Comunicação; Direitos humanos.

Keywords: LGBT Movement; Commemorations; Memories; Struggles; Communication; Human rights.

Palabras clave: Movimiento LGBT; Conmemoraciones; Memories; Luchas; Comunicación; Derechos humanos.

O movimento LGBT organizado comemorou, em 2018, 40 anos de atuação no Brasil. A historiografia consolidou como marco fundador da militância homossexual no país a criação do grupo Somos - Grupo de Afirmação Homossexual -, em 1978. A data levou à publicação de coletâneas, relançamento de livros, documentários e edições especiais de revistas e jornais, o que demonstra como a indústria cultural está em uma crescente e bem sucedida comercialização da memória.

Vivemos em uma sociedade marcada pela cultura da memória. Somos assombrados pelo medo de esquecer e o dever quase obsessivo de lembrar. Essa tendência à 'musealização' pode ser facilmente observada tanto em processos culturais coletivos como na vida privada, em que se busca, cada vez mais, gravar e arquivar as experiências ${ }^{1}$. 
Modificamos nossa forma de lidar com o tempo. Abandonamos a interpretação da história guiada pelo progresso, caracterizada por futuros presentes, em favor de uma relação temporal baseada em passados presentes ${ }^{2}$. Entre as novas características da cultura da memória está o imbricamento com as mídias. Discutir sobre memória pessoal ou pública sem levar em consideração a inter-relação com os meios de comunicação parece ter se tornado impossível. Tratando-se de passados presentes, percebe-se uma produção histórica cada vez mais numerosa sobre as efemérides, as comemorações.

Perante o novo regime, da memória hiperativada, devemos ter cautela com o papel que o passado exerce no presente. Nietzsche ${ }^{3}$ já alertava que a boa consciência e a capacidade de confiar no futuro depende da justa medida entre saber esquecer no momento preciso e se lembrar quando necessário. Frente a essa conjuntura, uma pergunta se faz central: quais são os efeitos de sentido das comemorações dos 40 anos do movimento LGBT (Lésbicas, Gays, Bissexuais e Transsexuais) no Brasil?

O historiador francês Marc Muller4, ao se voltar para o fenômeno das comemorações de datas de aniversário na América Latina, enfatiza que o elemento atravessador de todo esse campo de análise é a afirmação de uma identidade que se busca, uma identidade que se constrói afirmando-se. Os 'eventos de aniversários' reafirmam a coesão do grupo pelos padrões históricos (culturais, sociais e políticos). Os membros da comunidade seriam seduzidos a se apropriarem de um credo unificador. Seria o recall dos valores compartilhados por meio da atualização dos eventos fundadores do grupo. O ritual comemorativo é, portanto, uma estratégia de despertar e construir uma identidade 4 .

Contudo, nesse processo identificatório, cuja fonte é a memória coletiva, um grupo é sempre definido diferenciando-se de outro (membro externo, corpo estranho). Dessa forma, o aniversário deixa de ser apenas uma construção da identidade por meio do rememorar coletivo de um acontecimento considerado fundador para ser também um meio de consolidar ou defender uma diferença. A história narrada nas comemorações tem sua face obscura, marcada por silenciamentos e apagamentos. Ricoeur ${ }^{5}$ já alertava que a estrutura comemorativa é marcada por uma ideologia que, muitas vezes, aciona uma imaginação social comprometida com a justificação de uma autoridade. No entanto, as narrativas produzidas nas celebrações conseguem, na maioria das vezes, obscurecer as manipulações históricas em curso.

É cada vez mais recorrente que indivíduos e organizações formadas por gays, lésbicas, bissexuais, transgêneros e queer se voltem para as histórias públicas de seus passados, aparentemente compartilhados, a fim de defender mudanças políticas, sociais e culturais no presente. Um testemunho da necessidade de e da luta por essas mudanças está registrado na entrevista concedida para esta edição pela pesquisadora Luma Nogueira de Andrade. Em 'Assujeitamento e disrupção de um corpo que permanece e resiste: possibilidade de existência de uma travesti no ambiente escolar', a entrevistada traça uma trajetória discursiva e interseccional entre a sua vivência e a pesquisa científica.

Muito parecido com nações, instituições e outros segmentos minoritários antes dos grupos LGBTQ, conforme observa $\mathrm{Duhn}^{6}$, tais grupos perceberam que a comunicação de seus passados é um recurso para alavancar suas causas. $\mathrm{O}$ autor aborda, em termos mais gerais, os desafios e as oportunidades ao se adotar representações históricas de indivíduos e comunidades LGBT como uma estratégia política e, de modo particular, tais desdobramentos para uma comunidade diversificada, cujo passado é repleto de conflitos, lembranças, esquecimentos, silenciamentos e apagamentos, e marcado pelos traumas da pandemia de HIV/ aids e políticas representacionais, na maioria das vezes, divisivas de identidades fluidas, interseccionais.

A nota de conjuntura 'Sobre a (homo)sexualidade nos meios de comunicação (1980-2010)', de Alexandre Sebastião Ferrari Soares, trata do lugar do jornalismo, especialmente, como instância semantizadora das identidades homossexuais em suas conexões com a epidemia de HIV/aids. Entre continuidades e descontinuidades, os discursos sobre o vínculo entre a doença e a homossexualidade contam, recorrentemente, com aspectos implícitos, pré-construídos por meio de elementos citados e relatados, em remissões e retomadas. Esse processo reforça ideologias, representações e posições de sujeitos, mas, como 
bem mostra Soares, faz parte de um processo de movimentos de luta e contestação. No texto, o pesquisador aborda a relação entre a homossexualidade e a imprensa no Brasil, levando em consideração as conclusões que um analista do discurso pode oferecer para a sociedade, ao repensar a memória de sentidos causados pelas palavras 'homossexualismo' e 'homossexualidade', e já anunciando que as noções de produção e sentidos da memória se tornam indispensáveis para a construção e significação das identidades.

Como um exemplo de história que precisa ser narrada, é importante destacar que no Brasil o movimento em defesa dos direitos LGBT eclodiu como um ato de resistência em plena ditadura militar, marcada pela repressão e por ideais conservadores ${ }^{7}$. Nesse contexto, começou a haver especialmente ao final da década de 1970 a consolidação de movimentos identitários que estabelecerem novas agendas públicas (movimento negro, movimento feminista, movimento homossexual). Nesse cenário, de resistência e reconfiguração da esquerda, o grupo Somos inicia suas atividades na cidade de São Paulo.

Entre as reivindicações desse novo cenário político, a busca por visibilidade passa a ser compreendida como um dos elementos fundamentais para a conquista da cidadania. Os grupos militantes passam a defender que os direitos políticos, sociais e civis só se tornam legítimos socialmente para os cidadãos quando são perpassadas pelo direito à comunicação, sobretudo na nossa sociedade na qual é através das mídias que se torna possível promover o eco social. Dessa forma, o direito à comunicação se constituiria, ao mesmo tempo, em "direito civil - liberdade individual de expressão; em direito político - através do direito à informação; e em direito social - através do direito a uma política pública garantidora do acesso do cidadão às diferentes formas de comunicação mediadas tecnologicamente".

Considerando a visão da comunicação como fator de humanização, Maria Eugênia Porém e Guilherme Lopes Teixeira, autores do texto 'Travestis e organizações: o papel da comunicação na construção de espaços organizacionais' refletem sobre o potencial transformador da comunicação e sobre a necessidade do comunicador atual promover espaços de diálogo e inclusão nas organizações. Os autores produzem um esboço de diretrizes comunicacionais para a criação de um ambiente preparado para receber a travesti, valorizá-la e reconhecê-la como indivíduo e também como parte de um todo.

Ao analisar os entraves para o estabelecimento de uma democracia plena no Brasil, Paulo Freire já havia notado que desde a sua colonização o país vive sob um sistema comunicacional de "mutismo", em que os oprimidos não têm direito à voz, logo, não conseguem romper as amarras da cultura que os domina e subjuga. A crença no papel transformador da comunicação fez com que as práticas da militância homossexual privilegiasse o campo comunicacional. Assim, refletir sobre o movimento homossexual significa, em grande medida, pensar nas suas articulações com as mídias, suas práticas e processos, assim como discutido nesta edição, no texto de Bruno Leal de Souza e Carlos Camargos Mendonça, 'Dilemas da visualidade jornalística das violências contra pessoas LGBTQ+ e contra mulheres heterossexuais no Brasil'. Os autores analisam as diferentes formas de visibilidade da violência de gênero em jornais impressos e concluem que essa diferença se dá pela relação distinta de normalidade e anormalidade atribuída a corpos de pessoas dos dois grupos estudados.

A própria trajetória do grupo Somos está diretamente ligada à mídia. O grupo, que, em sua fase embrionária se chamava 'Núcleo de Ação pelos Direitos dos Homossexuais', teve como primeiro ato público o envio de uma carta protesto destinada ao sindicato dos jornalistas em que criticavam a forma como a imprensa costumeiramente tratava os homossexuais ${ }^{10}$. A relação com a imprensa não ocorria somente por meio de críticas, o grupo também produzia seus próprios jornais como forma de divulgar as ações desenvolvidas e promover os ideais da militância homossexual. Para além do plano das ações empreendidas, a consolidação do Somos também é creditada a um fenômeno comunicacional, o surgimento do 'Lampião da Esquina' meses antes.

A simbiose observada na relação do Somos com a mídia passa também a ser notada nos outros grupos de ação em prol dos direitos homossexuais que se espalharam pelo país. Durante a década de 1980, pelo 
menos, dez grupos ligados ao movimento homossexual brasileiro lançaram publicações e tinham como uma de suas pautas os regimes de visibilidade da homossexualidade, sendo eles: o 'Gatho' do Grupo de Atuação Homossexual, o 'ChanacomChana' e o 'Informativo Associação Galf' do Grupo de Ação Lésbico Feminista, o 'Nós Também' do Grupo Nós Também, o 'Facção Homossexual' do grupo Facção Homossexual ligado à Convergência Socialista, 'Boletim do G.G.B' do Grupo Gay da Bahia, o 'Boletim Informativo do Grupo Dialogay' do Grupo Dialogay, o 'Triângulo Rosa' do Triângulo Rosa, o 'Jornal do Jatobá' do Movimento de Emancipação Homossexual e o 'Boletim Informativo LAMBDA' do Movimento pela Livre Orientação Sexual' ${ }^{11}$.

O pioneirismo e o protagonismo do Somos e do 'Lampião', na proposição de um modelo de militância que se implementaria nesses primeiros anos de movimento homossexual, colaboraram para que fosse criada em torno deles uma áurea de mito fundador da luta em prol das dissidências de gênero e sexualidade no país. Ferreira ${ }^{12,13}$ já demonstrou os riscos de se pensar e escrever a história por meio do estabelecimento desses mitos fundadores que parecem bastar para explicar, justificar e condenar. A complexidade dos acontecimentos históricos tende a ser desconsiderada nessas narrativas que produzem uma história generalista e totalizadora marcada por apagamentos ${ }^{12,13}$.

Desde o seu surgimento, o movimento social de luta pelo reconhecimento da diversidade sexual e de gênero passou por transformações profundas. A articulação de coletivos inicialmente identificada como o Movimento Homossexual Brasileiro (MHB) passou a se denominar de Movimento LGBT, reflexo da multiplicação das bandeiras de luta e dos personagens envolvidos nas reivindicações.

O retorno político ao Estado democrático e a necessidade de responder a epidemia da aids levou a uma reorganização do movimento, com um maior diálogo socioestatal. A gramática política utilizada teve que se adequar às instâncias estatais, com ênfase na clara definição das identidades que formariam esse segmento e para quais delas as políticas públicas seriam destinadas. Como consequência, as disputas por visibilidade no interior do movimento foram acirradas. As demandas da população lésbica, travesti, transexual e bissexual passaram a colocar em questão o predomínio dos gays e da associação do movimento a uma dada versão muito respeitável das homossexualidades ${ }^{14}$.

Os esforços empreendidos para que a população LGBT goze de direitos plenos conquistou, nas últimas décadas, resultados positivos como a possibilidade da realização do casamento entre pessoas do mesmo sexo, a adoção de crianças por casais homossexuais e a retirada da homossexualidade da lista de doenças do então Instituto Nacional de Assistência Médica da Previdência Social (Inamps), como podemos ver no artigo de Carlos Alberto Carvalho e José Henrique Pires Azevêdo, 'Do AZT à PrEP e à PEP: aids, HIV, movimento LGBTI e jornalismo', em que os autores relembram a vitória da expansão do termo 'grupo de risco' na literatura médica para o combate e prevenção do HIV/aids ao longo da história, ainda que percebam manutenções de preconceitos históricos na cobertura jornalística sobre o tratamento e a prevenção da aids. Certos avanços são igualmente constatados na divulgação da décima primeira edição da Classificação Estatística Internacional de Doenças e Problemas Relacionados com a Saúde (CID-11), em junho de 2018. No texto 'Notícias sobre a nova classificação das identidades trans: uma análise das fontes citadas em reportagens publicadas no Brasil, Tatiana Clébicar Leite e Katia Lerner analisam, por meio da cobertura jornalística da divulgação do CID-11, que, embora as identidades trans tenham deixado de ser classificadas como doenças mentais, a despatologização ainda é marcada por processos de medicalização e biomedicalização.

Podemos perceber que as conquistas recentes vêm acompanhadas do aumento da intolerância e dos crimes de ódio, como nos mostra Ettore Stefani no artigo 'Necropolítica tropical em tempos pró-Bolsonaro: desafios contemporâneos de combate aos crimes de ódio LGBTfóbicos', ao expor como as minorias sociais passam a ser alvo de grandes agressões na atualidade, legitimada por uma política de morte e simbolizada pela mídia em uma forte disputa política e, por vezes, religiosa, discutida também por Aline Roes Dalmolin, Marina Martinuzzi Castilho, Márcia Zanin Feliciani no texto 'Nós versus eles: ódio biopolítico contra a 
população LGBT no Twitter de Marco Feliciano'. Esse tipo de discurso de ódio é proferido por um grupo que se julga dominante e exclui o que considera diferente em nome da sua perpetuação e da conservação de seus valores. Líderes neopentecostais midiáticos e políticos da direita conservadora vêm sistematicamente promovendo o discurso de detração a todos os corpos que não se enquadram na heteronorma. Projetos de lei para criminalizar a homofobia, como a PLC 122, são barrados pela bancada evangélica enquanto a cada 19 horas um LGBT é assassinado ou se suicida vítima da LGBTfobia, segundo dados do Grupo Gay da Bahia ${ }^{15}$. No entanto, como o campo de lutas se dá em movimentos, contradições e instabilidades, entre rupturas e continuidades, conservadorismos e progressismos, no dia 13 de junho de 2019, o Supremo Tribunal Federal, por oito votos a três, determinou que a homofobia passe a ser punida pela Lei de Racismo (7716/89), que hoje prevê crimes de discriminação ou preconceito por "raça, cor, etnia, religião e procedência nacional"16.

O dossiê '40 anos do movimento LGBT no Brasil: comunicação, saúde e direitos humanos' publicado nesta edição da Reciis teve como objetivo reunir trabalhos que rememoram criticamente os marcos temporais dessa história de criação de identidades e, ao mesmo tempo, de apagamentos e demarcações de diferenças. Buscamos promover o debate acerca dos acontecimentos dessa história em curso para ajudar a refletir sobre os desafios do presente e trilhar caminhos para o futuro.

A chamada pública ao dossiê recebeu uma oferta de textos tanto diversa quanto qualificada. Diante do grande número de textos aprovados, decidimos dividi-lo em duas partes de modo a continuar garantindo espaço na edição regular da Reciis para outros textos.

Esta edição conta, portanto, com um conjunto diversificado de textos em outras seções, enviados sob o regime de fluxo contínuo de submissões. Entre os artigos originais, temos um texto que aborda as relações entre comunicação e saúde pela mídia, em 'Síndrome de Mayer Rokitansky Küster Hauser: estigma, corpo, mídia e bioética', de Daniela Amado Rabelo e Natan Monsores, e outro que considera tais relações a partir da sociabilidade: 'Doce Veneno: uma análise do consumo de bebidas açucaradas por adolescentes', de Thaína Rocha Balbino e Stephanie Ingrid Souza Barboza. Há um texto nas interfaces entre informação e saúde: 'Quality of websites for gamete donation', de Inês Baía, Catarina Samorinha, Cláudia de Freitas, Helena Machado, Isabel Sousa Pereira e Susana Silva. Ainda há espaço para um texto sobre o processo de produção científica: 'Apoio a projetos de divulgação científica: análise de edital realizado pela Fundação Oswaldo Cruz', de Luisa Massarani, Willian Vieira de Abreu e Jessica Noberto Rocha.

Outras seções da revista trazem textos igualmente interessantes: um ensaio' "Saúde digital: interseções entre a pesquisa científica e sua midiatização', de Alessandra de Falco Brasileiro Lermen; um artigo de revisão, 'Mapeamento sistemático: sistemas de áudio e vídeo para o ensino de crianças portadoras do Transtorno do Espectro Autista', de Rafael Moura Toscano e Valdecir Becker; um relato de experiência sobre a produção de vídeo educacional na formação docente para o ensino na saúde e, por fim, uma resenha sobre o documentário Mulheres da Águas, que discute comunidade, gênero e raça a partir da história de pescadoras nos manguezais no nordeste do país.

A Reciis, a partir deste ano, procurará contar em todas as suas seções com textos. Recebemos textos afinados com nosso escopo temático em fluxo contínuo e a partir das chamadas públicas para dossiês temáticos.

\section{Referências}

1. Ribeiro APG. A memória e o mundo contemporâneo. In: Ribeiro APG; Freire Filho J.; Herschmann M., organizadores. Entretenimento, Felicidade e Memória: forças moventes do contemporâneo. 1 ed. São Paulo: Anadarco; 2012. p.64-84.

2. Huyssen A. Seduzidos pela memória: arquitetura, monumentos, mídia. Rio de Janeiro: Aeroplano; 2000.

3. Nietzsche F.Segunda consideração intempestiva: da utilidade e do inconveniente da história para a vida. São Paulo: Editor Escala; 2008. 
4. Muller M. Le phénomène commémoratif: enjeu d'une quête sociale d'identité. Autres Temps. 1998:(57):17-24.

5. Ricoeur P. A ideologia e a utopia. Belo Horizonte: Autêntica Editora; 2017.

6. Duhn T. Queerly remembered: rhetorics for representing the GLBTQ past. Columbia: University of South Carolina Press; 2016.

7. Green J; Quinalha R, organizadores. Ditadura e homossexualidades: repressão, resistência e busca pela verdade. São Carlos: Edufscar; 2014.

8. Lima VA. Da cultura do silêncio ao direito à comunicação. Observatório da Imprensa [Internet]. 2011 [citado em 2019 jun. 25]: ed.669. Disponível em: http://observatoriodaimprensa.com.br/feitosdesfeitas/da-cultura-do-silencio-ao-direito-a-comunicacao/

9. Freire P. Educação como prática da liberdade. Rio de Janeiro: Paz e Terra; 1967.

10. MacRae E. A construção da igualdade: política e identidade homossexual no Brasil da "abertura". Salvador: EDUFBA; 2018.

11. Ferreira VRC. Imprensa homossexual brasileira e construções de subjetividades (1960-1980). [dissertação]. Rio de Janeiro: Universidade Federal do Rio de Janeiro; 2017.

12. Ferreira VRC. Por uma história cultural da imprensa homossexual. In: Rego AR; Guillamet J et al., organizadores. Os desafios da pesquisa em história da comunicação: entre a historicidade e as lacunas da historiografia. 1 ed. Porto Alegre: EdiPUCRS; 2019. p. 405-39.

13. Ferreira VRC. Pleiguei e a influência do pink money nas configurações da imprensa homossexual brasileira. In: Rêgo AR; Leal R; Ferreira VRC et al., organizadores. Mídia: Narrativas, Discurso e História. Curitiba: APPRIS; 2019. p. 121-32.

14. Facchini R. Múltiplas identidades, diferentes enquadramentos e visibilidades: um olhar para os 40 anos do movimento LGBTI. In: Green JN; Quinalha R.; Caetano M. et al., organizadores. História do movimento LGBT no Brasil. 1 ed. São Paulo: Alameda, 2018. p. 311-30.

15. Grupo Gay da Bahia. Mortes violentas de LGBT no Brasil: relatório 2017 [Internet]. 2017 [citado em 2019 jun. 25]. Disponível em: https://homofobiamata.files.wordpress.com/2017/12/relatorio-2081.pdf

16. Presidência da República (BR). Casa Civil. Lei no 7.716, de 5 de janeiro de 1989. Define os crimes resultantes de preconceito de raça ou de cor. DOU [Internet]. 1968 jan. 06 [citado em 2019 jun. 25]. Disponível em: http://www.planalto.gov.br/ccivil 03/leis/l7716.htm 